\title{
Predicting the Defeatists Behavior Through Self-Esteem: Undergraduate Female Students Majoring in Kindergarten at Al-Hussein Bin Tala University
}

\author{
Reham Almohtadi ${ }^{1}$, Intisar Turki ALdarabah ${ }^{1}$, Mustafa Jwaifell ${ }^{1}$ \& Ruba Nasser Masri Shaarani ${ }^{2}$ \\ ${ }^{1}$ Faculty of Education, Al-Hussein Bin Talal University, Jordan \\ ${ }^{2}$ Faculty of Education, Lebanese University, Lebanon \\ Correspondence: Intisar Turki ALdarabah, Faculty of Education, Al-Hussein Bin Talal University, Jordan.
}

Received: May 13, $2019 \quad$ Accepted: June 26, $2019 \quad$ Online Published: November 29, 2019

doi:10.5539/ies.v12n12p113 URL: https://doi.org/10.5539/ies.v12n12p113

\begin{abstract}
The study aimed at predicting the defeatist behavior through determining self-esteem among undergraduate female students majoring in kindergarten at Al-Hussein Bin Talal University. The descriptive correlative method was used to accomplish the study's findings. The study sample consisted of 41 female students of the academic year (2018/2019). For the purpose of collecting data, two scales were used: the first one is Rosenberg's (1989) scale for self-esteem and the second is Kabatay's (1999) scale to measure the students' defeatist behavior. Results of the study showed that self-esteem among the female students is at a lower level, whereas their level of defeatist behavior is medium. The results also showed that there was an inverse correlation between self-esteem and the defeatist behavior.
\end{abstract}

Keywords: defeatist behavior, self-esteem, female students majoring in kindergarten

\section{Introduction}

The reason for many researchers' interest in studying self-esteem variable and its influence on individuals causing them experience changes or transformations and crisis, is that self-esteem is a positive trait in the personality that has a correlation with other positive traits. University adults are identified to embrace certain needs, trends, and lifestyle that differ from other categories. Hence, if those needs are not satisfied, this may generate the feeling of defeatism and disappointment (Al-Tameemi, 2013).

Defeatist behavior means that the individual surrenders to negative defeatist thoughts and lacks the basis for his mental purity and all the defensive tricks. As if he looks through a distorted window, instead of viewing reality clearly, he perceives a distorted, ambiguous and unclear image of reality, which in turn leads to lower levels of self-esteem (Fakhri, 2014).

Self-esteem is considered as one of the basic human needs which everyone seeks to fulfill and exerts great efforts to attain it. This fact has been asserted by Maslow (1970) in his theory about human's basic needs, which he classified in a pyramidal sequence according to the individual's priority in terms of satisfying them. The pyramid begins with the physiological needs then the need for love and belonging, the need for esteem, and finally need for self-esteem. The final need according to Maslow's theory indicates the individual's wish to satisfy particular feelings of trust and eligibility, through which feelings of strength, accomplishment, competence, freedom, trust and sovereignty in facing the world are achieved (Chang, 2006). Pattan et al. (2006) indicate that self-esteem reflects the individual's feelings of his worth or self-respect, and to what extent s(he) admires and loves him/herself. There are certain concepts used to reflect self-esteem like appreciating the external appearance or the body.

\subsection{Study Problem and Its Questions}

Adults in general suffer the crisis of goals loss and especially after the social and political crises that took place in the Arab world and its social construction, which in turn might reflect negatively on self-esteem. Other psychological studies introduced the difficulties faced in drawing a clear picture of the individuals' self-esteem and its relation with some variables such as the defeatist behavior. Thus, can the individual maintain a fixed level of self-esteem along his different age stages? To answer this question, researchers tend to determine the levels of 
self-esteem among university's students to find out the related variables that contribute to its rise or decrease. This very important variable is the personality of this segment of adults which represents the society's strength and the pillars of its structure.

We need more studies and researches that encourage adults achieve healthy and intact life, along with a strong psychological construct that helps the individual confront this stage of changes, crises and challenges that might seem to be too difficult to tolerate.

Problem of this present study revolves around the following questions:

1) What is level of self-esteem among undergraduate female student's major kindergarten at Al-Hussein Bin Talal University?

2) Is it possible to predict the defeatist behavior through level of self-esteem among the female students majoring in Kindergarten at Al-Hussein Bin Talal University?

\subsection{Research Objectives}

Objectives of this present study were determined in the follow:

1) Unveiling level of self-esteem among the female students majoring in Kindergarten at Al-Hussein Bin Talal University.

2) Unveiling level of their defeatist behavior.

3) Unveiling the nature of the relation between self-esteem and defeatist behavior.

\subsection{Research Importance}

The significance of this study is manifested by the importance of its topic which is predicting the level of the defeatist behavior through determining the level of self-esteem among female students majoring in Kindergarten at Al-Hussein Bin Talal University, and how to confront it in the shadow of the current situation in society, especially with the need for healthy and strong individuals having cognitive capabilities. Also the limited number of studies in this field makes it a fruitful field to explore in terms of different perspectives relevant to the study. The importance of this study stems from the fact that the defeatist behavior has widely spread among adults resulting later in many academic, psychological and social problems. On the practical level, the study might direct and attract the attention of psycho-educational science specialists to the importance of this segment in adults, by preparing the different counseling programs to develop this side in the personality, modify their defeatist behaviors, and prepare the programs to develop self-esteem at other age stages, in addition to other positive sides.

\subsection{Theoretical Frame and Literature Review}

\subsubsection{Defeatism Behavior}

Early disorder in warm relationships such as the lack of love and empathy between the mother and the child at the early years develop weak congruence between them specifically, and between him and the family as a whole generally. This experience makes the individual surrender to the defeatism behavior, escaping from reality, and feeling guilt and social isolation (Williams, 1980). Abu-Halawa (2013) defines the defeatism behavior as a psychological state with cognitive and emotional implications represented in feelings of deficit, helplessness, and lack of effectiveness. This behavior results in the individual encountering traumatic and stressing life events especially if he has fragile and weak psychological structure and inappropriate social upbringing. Defeatism reflects on the individual and on his relationships with others as he becomes untrustworthy and unable to form sound social relationships, turning him into a dependent individual who feels worthless and acting in reactions often unclear and do not explain the stimuli he is exposes to it. Meifen and Tsun (2007) and Al-Mtairi (2010) indicate that there are many actions the defeatism individual performs, such as: loss of trust, shaking the head a lot as a sign of agreement, divergent eyes, closed eyelids, cold and disturbing hands, soft in speaking and in a hesitation state.

Psychological defeatism behavior is considered as one of the most dangerous and severe feelings among university students, because negative emotions and weakness related to this state might make them subject to many psychological and social disorders which in turn prevent the achievement of psychological health, and might force the individual to blame himself and reside the feelings of inability as a means to escape from facing failure. As a result, he inclines to marginalize his strength and capabilities; which make him lose hope and ambition and get used to pain, which negatively affects his psychological flexibility and weakens his ability to achieve psychological steadfastness (Al-Shafi, 2017). 


\subsubsection{Self-Esteem}

Self-esteem is considered as an evaluative concept that basically depends on how the individual evaluates himself. These evaluations might be positive or negative, since self-esteem is influenced by the degree of reaching the personal standards and goals. It also plays a central role to the psychological health, which appears highly during the childhood stage, then gradually declines during adolescence, gradually increases during the adult's state, and deteriorates and regresses at senility (Robins et al., 2002).

Al-Zu'bi (2005) identifies self-esteem as a group of attitudes and beliefs the individual bears for himself, which is considered very important to his relationships with his parents, teachers, friends and other people inside and outside the society. Heritage (2013) indicates that self-esteem term means the evaluation the individual sets for himself and by himself and works to maintain; it is a term that expresses the individual's positive and negative attitudes, his belief in his ability, importance, success and competence (has a merit).

Benyamini and Leventhal (2004) stated that self-perception is characterized by taking the good and rejecting the hideous. However, the balance between the two processes is not completely guaranteed since the increase in once side results in the decrease in the other side, for this reason we find that self-esteem is subject to self-dynamic factors influencing it.

There are two types of factors leading to identifying high or low self-esteem, which are:

1) Factors relating to the individual himself: it is asserted that degree of self-esteem in the child is determined by the amount of absence of worry or the psychological stability, which means if the individual enjoys good psychological health, this will enhance his normal growth, and his self-esteem will be high, whereas if the individual suffers worry and instability, then his perception of the ego will be low, and his self-esteem is low as well.

2) Factors related to the external environment: more concerned with the social upbringing conditions in which the child is raised and the type of education received. For instance, is he allowed to participate in family affairs? Does he decide what he needs? What is the type of punishment imposed on him? And what is the family's view of the individual's friends, love or hatred? (Sa'aydeh, 2007).

Based on review of some literatures that have addressed this concept, levels determined by Coppersmith (1981) will be illustrated:

(1) High self-esteem: Here, the individual considers himself important and deserves respect, appreciation and consideration, he has sufficient idea about what he thinks is right, he always enjoys the challenge, and does not fear or stay away from misfortunes.

(2) Low self-esteem: Here, the individual considers himself not very important, unloved, unable to do the things he actually wants to do, he believes that what others have is better than what he has especially in terms of capabilities, aptitudes and competences.

(3) Medium self-esteem: People of this type fall between the other two types, and self-esteem is determined by their ability to do the things required from them (Coppersmith, 1981).

One of the theories that have an interest in studying self-esteem is Abraham Maslow's theory about the human needs, since the thought that both the psychological and behavioral analysis theories focused their studies on searching the negative and sick and animal sides in the individual. The analysts see the human as a victim of animalistic instincts and conflicts launched by the civilization in himself. So, behaviorists see the human as a living organ whose behavior was formed by the environment; this is why Maslow tended to study the positive sides of the human personality. His theory is based on studying healthy self-actualized individuals (Maslow, 1970).

Here's an illustration of the five levels of the paramedical organization of the human needs as mentioned by (Hamid et al., 2015).

1) Physiological Needs- Directly related to survival, including hunger, sex, thirst, need for Oxygen, and excrete.

2) Safety Needs: When people satisfy their psychological needs they are pushed by the safety needs to guarantee the body security, stability, independence and protection from illness, fear, worry, danger, and disturbances.

3) Belonging and love Needs: People are induced by love and belonging represent in their desire for friendship, marriage and special desires for family, neighborhood and belonging to the clan.

4) Esteem Needs: People launch to achieve self-esteem after achieving the previous levels of needs.

5) Self-Actualization Needs: This need represents the top of the paramedical sequence of the needs; it includes the discovery, optimal usage of the individual's energies and innate capabilities. 
This need expresses the individual's desire and tendency to achieve this capabilities to become real fact.

\section{Literature Review}

Mohammad (2016) study aimed to find out the irrational ideas among the female students major kindergarten and their defeatist behavior, and the nature of the relationship between the irrational ideas and the defeatist behavior. Study sample consisted of 200 female students.

Results indicated at the presence of high defeatist behavior, and the presence of positive correlation between the irrational ideas and the defeatist behavior among the female students.

Hasan and Ali (2014) conducted a study aimed to know the social anxiety and its relationship with self-esteem among the female students at Faculty of physical Education at Al-motha'ona University in Iraq, Results showed the appearance of social anxiety level, the presence of significance in self-esteem, and the inverse correlation between social psychological anxiety and self-esteem among the students.

Mik et al. (2010) conducted a study which aimed at disclosing level of defeatist among a sample of students from Slanjoor University in Malaysia. Results showed that most of the students enjoy good personality from the psychological level, and that the level of defeatism is very law, in addition to the presence of differences with statistically significance between urban and rural students, where rural students had less level of defeatist behavior than urban students.

\section{Procedures of the Study}

\subsection{Study Methodology}

This research depends on the descriptive correlative method because of its relevance to the study and its objectives since it aims to determine the level of self-esteem among undergraduate female students, and the attempt to know the extent of the correlation between self-esteem level and the defeatist behavior.

\subsection{Study Sample}

Study sample consisted of all the 41 undergraduate female students majoring in Kindergarten at Al-Hussein Bin Talal University of the academic year 2018/2019.

\subsection{Study Instrument}

The two study's instruments were introduced to a group of universities professors arbitrators specialized in educational psychology science, counseling, behavior medication, and evaluation; to assure relevance of the items with its dimensions and its linguistic wording.

\subsubsection{First Study Instrument}

Self-Esteem is measured using the Rosenberg's (1989) scale which is developed by setting a scale for self-respect and acceptance among adolescents, and then it was expanded to be used for (Adults). It included 10 items; five negative items with fourfold step-wise (0-3), starts from strongly disagree and ends with strongly agree, the degree ranges from 0 to 30 , self-esteem level is calculated if the testers receive the degree 15 and less with low evaluation, and the degree higher than 15 average evaluation and higher.

The scale has good cicometric characteristics in its English wording (Blascovich \& Tomaka, 1991), and the Arabic wording (Abdel-Khalek, Korayem, \& El-Nayal, 2012).

The answer to this scale is according to the original step-wise with fourfold step-wise.

The scale included ten items as follow:

1) I feel that I'm a person of worth, at least on an equal plane with others.

2) I feel that I have a number of good qualities.

3) All in all, I'm inclined to feel that I'm a failure.

4) I'm able to do things as well as most other people.

5) I feel I do not have much to be proud of.

6) I take a positive attitude toward myself.

7) On the whole, I'm satisfied with myself.

8) I wish I could have more respect for myself.

9) I certainly feel useless at times. 
10) At times I think I'm no good at all.

\subsubsection{Second Study Instrument: Defeatist Behavior Scale}

This scale is used based on (Kabatay, 1999) scale, also on the previous educational literature such as (Al-Tameeni, 2013; Al-Dojaili \& Al-Ani, 2018). The scale consisted of 57 items distributed into (6) dimensions. It has been applied and reapplied after two weeks of the first application, calculating the correlation coefficients between the first application of total the defeatist behavior and for each dimension, and the correlation factors between the dimensions and the scale as a whole, extracting the internal consistency coefficient by calculating Cronbach's Alpha which reached (0.850), while Pearson reliability coefficient by re-applying reached $(0.873)$ which is a high and relevant for the study purposes.

Table 1. Cicometric tests for the defeatist behavior

\begin{tabular}{cccc}
\hline Defeatist Behavior & Number of the Clauses & By Repetition & The Dimension with the Total \\
\hline Feeling of guilt & 7 & $.575^{* *}$ & $.680^{* *}$ \\
Withdrawal & 9 & $.647^{* *}$ & $.761^{* *}$ \\
Self-destruction & 9 & $.643^{* *}$ & $.858^{* *}$ \\
Fear from failure & 10 & $.712^{* *}$ & $.846^{* *}$ \\
Law ego & 10 & $.636^{* *}$ & $.910^{* *}$ \\
Social isolation & 12 & $.523^{* *}$ & $.914^{* *}$ \\
Total & 57 & $.873^{* *}$ & \\
\hline
\end{tabular}

** Correlation is significant at $(0.01)$ level.

For the purpose of determining levels of the defeatist behavior, the scale's degrees were transformed into three categories as in Table 2.

Table 2. Categories of the defeatist behavior

\begin{tabular}{cccccc}
\hline Behavior Degree & Very High & High & Medium & Low & Very low \\
\hline Rank & 5 & 4 & 3 & 1 & 1 \\
Categories & $1-2.33$ & $2.34-3.66$ & $5-3.66$ \\
Level & Low & Medium & High \\
\hline
\end{tabular}

\section{Results of the Study and Their Discussion}

Results of the first question: What is level of self-esteem among undergraduate female students majoring in Kindergarten at Al-Hussein Bin Talal University?

To determine the students' level of self-esteem the means were calculated. The mean of the self-esteem scale reached (15.71) with standard deviation (2.25), which is higher than the mean (15) representation the higher bound to estimate the medium self-esteem and less. And to test the difference significance, (one sample t-test) is used, where $t$ value reached (2.003) with degree of freedom (40) statistically insignificant at significance level $(\propto<0.05)$, so the self-esteem among the female students majoring in Kindergarten falls at a lower level than the medium level. Since the low self-esteem forms real impairment to the individual, people at this level focus on their defects and on bad characteristics, they incline more to be influenced by the group pressures and listen to their opinions and judgments, they also set themselves lower expectations than the reality.

External conditions are direct reasons for such a result, including: (poverty, state of the society, and the disturbed family). All these conditions and others can create low self-esteem in individuals; but family factor plays the biggest role in creating low self-esteem. Individuals with low self-esteem are viewed by others as lacking control over their affairs, so it is most probably possible to influence them easily (Okasha, 1998, Moray, 1988). Also, the female students' low self-esteem can be contributed to factors related to body image and social standards, since the body image has an influence on self-concept, and is influenced by its objectivity features, such as the size, speed, muscular and neural coordination (Abu-Moghli, 2002).

Moreover, the nature of the study population (tribal society), and the nature of the social upbringing in it enhance the females' dependence culture, submission, feeling of weakness, and the necessity to resort to the man when facing difficult situations, which creates false beliefs and judgments about their ego as being unable to challenge, 
as well as the need for getting far away from the initiating culture, insistent and hardworking, and the necessity for exerting more efforts as much as possible (Abu-Ghali, 2012).

Results of the second question: what is the level of the defeatist behavior among female students majoring in Kindergarten at Al-Hussein Bin Talal University? To determine the level of the defeatists behavior, means and standard deviations were calculated for the total of defeatist behavior scale, and its dimensions, also (one sample t-test) is used to examine the apparent differences significance regarding the crucial score that represent the higher limit to the defeatist behavior level (see Table 2), the following table clarifies results of the differences significance.

Table 3. Means and standard deviations of the defeatist behavior $(\mathrm{N}=50, \mathrm{df}=49)$

\begin{tabular}{ccccccccc}
\hline Defeatist Behavior & Items & Mean & Std & Rank & Level & Crucial score & T value & Sig. \\
\hline Feeling of guilt & 7 & 3.57 & 0.53 & 3 & & & 14.911 & .000 (a) \\
Withdrawal & 9 & 3.55 & 0.58 & 5 & & & 13.359 & .000 (a) \\
Self-destruction & 9 & 3.61 & 0.39 & 1 & & & 21.076 & .000 (a) \\
Fear from the failure & 10 & 3.61 & 0.51 & 1 & Medium & 2.34 & 16.072 & .000 (a) \\
Low ego & 10 & 3.53 & 0.49 & 6 & & & 15.631 & .000 (a) \\
Social exclusion & 12 & 3.56 & 0.46 & 4 & & & 16.939 & .000 (a) \\
Total & 57 & 3.57 & 0.41 & & Medium & 2.34 & 19.330 & .000 (a) \\
\hline
\end{tabular}

One sample t-test results show that the crucial score (2.34) represents the higher limit of the weak defeatist behavior category, all the means for the defeatist behavior and its dimensions fall in the medium category and with statistical significance. Therefore, the level of the defeatist behavior among female students majoring in Kindergarten at Al-Hussein Bin Talal University falls in the medium category of the defeatist behavior.

This can be explained by what has been found in Macfie et al. (2001) that self-defeatism increases among individuals who were subject to mistreatment (by parents or by care providers). This can lead to different development course, it must be mentioned here that the childhood age is a sensitive stage during which the ego is developed either as defeatist or stable.

Also, the defeatist ego influences the individuals' ideas, attitudes, feelings and behaviors which results in their failure to satisfy the basic needs, whether the need for respect, love, belonging, dominance, or acceptance. This failure leads to psychological problems like worry, depression, social isolation, and other external problems. Despite the wide variety of the possible symptoms that reflect defeatist ego, the most common ones are frustration, decreased hope, and self-efficacy deficit regarding future attempts to change the situation.

In light of this, the ego's defeatist behavior might reflect a negative course with self-continuity. For instance, whenever the individual attempts to satisfy hard-reaching needs, he feels frustration, disappointment, and lack of the desired control (Brownson \& Hartzler, 2000). Blascovich and Tomaka (1991) see that the destruction tendency may lead to self-defeatism or aggression, and that self-defeatism evolves when the behavior goes against what the parents have taught their child, arousing feelings of guilt and fear of punishment, which force the child to impose blame and criticism on himself (Lahey, 2000).

Also, having friends and peers characterized by negative thinking and attitudes to life is another reasons for self-defeatism, because the defeatist finds more comfort with those who support his opinion, because their ideas and behaviors are of the same kind, leading the individual to face greater challenges, turning his life into a chain of troubles (Atkinson, 2017).

Results of the third question: Is it possible to predict the defeatist behavior (feeling of guilt, withdrawal, self-destruction, fear of failure, social exclusion \& low ego) through the level of self-esteem among female students majoring Kindergarten at Al-Hussein Bin Talal University?

Means and standard deviations were calculated for self-esteem degrees and the defeatist behavior among female students, and calculating correlation coefficient between self-esteem degree and defeatist behavior and its dimensions, as seen in the following table. 
Table 4. Means and standard deviation for self-esteem and the defeatist behavior

\begin{tabular}{cccccccc}
\hline Defeatist Behavior & Mean & Std & $\mathrm{R}$ & Sig. & $\mathrm{R}^{2}$ & $\begin{array}{c}\text { Adjusted } \\
\mathrm{R}^{2}\end{array}$ & Std Error \\
\hline Feeling of guilt & 3.57 & 0.53 & -0.405 & .004 & 0.164 & 0.143 & 0.48820 \\
Withdrawal & 3.55 & 0.58 & -0.620 & $0.000(\mathrm{a})$ & 0.384 & 0.368 & 0.46201 \\
Self-destruction & 3.61 & 0.39 & -0.711 & $0.000(\mathrm{a})$ & 0.506 & 0.493 & 0.27517 \\
Fear from the failure & 3.61 & 0.51 & -0.714 & $0.000(\mathrm{a})$ & 0.510 & 0.498 & 0.35850 \\
Low ego & 3.53 & 0.49 & -0.728 & $0.000(\mathrm{a})$ & 0.529 & 0.517 & 033987 \\
Social exclusion & 3.56 & 0.46 & -0.741 & $0.000(\mathrm{a})$ & 0.549 & 0.537 & 0.31298 \\
Total & 3.57 & 0.41 & -0.794 & $0.000(\mathrm{a})$ & 0.613 & 0.622 & 0.25095 \\
\hline
\end{tabular}

The above table shows Pearson's correlations coefficients significances between self-esteem and the defeatist behavior, with the presence of inverse correlation, so the simple regression analysis is used.

The table shows that $\mathrm{R}^{2}$ value (The $\mathrm{R}^{2}$ column) varies according to the dependent variables; it can be explained by the independent variable. ANOVA analysis is conducted as seen in Table 5.

Table 5. ANOVA $(\mathrm{n}=41, \mathrm{df}=1.39)$

\begin{tabular}{cccccc}
\hline Predictors & Source of Variance & Sum of Square & Mean Square & F & Sig. \\
\hline \multirow{2}{*}{ Feeling of guilt } & Regression & 1.827 & 1.827 & 7.665 & 0.009 \\
& Residual & 9.295 & 0.238 & & \\
Withdrawal & Regression & 5.193 & 5.193 & 24.330 & $0.000(\mathrm{a})$ \\
& Residual & 8.325 & 0.213 & & \\
Self-destruction & Regression & 3.025 & 3.025 & 39.956 & $0.000(\mathrm{a})$ \\
& Residual & 2.953 & 0.076 & & \\
Fear from the failure & Regression & 5.224 & 5.224 & 40.643 & $0.000(\mathrm{a})$ \\
& Residual & 5.012 & 0.129 & & \\
Low ego & Regression & 5.067 & 5.067 & 43.870 & $0.000(\mathrm{a})$ \\
& Residual & 4.505 & 0.116 & & \\
Social exclusion & Regression & 4.644 & 4.644 & 47.413 & $0.000(\mathrm{a})$ \\
& Residual & 3.820 & 0.098 & & \\
Total Defeatist Behavior & Regression & 4.203 & 4.203 & 66.736 & $0.000(\mathrm{a})$ \\
& Residual & 6.659 & 0.063 & & \\
\hline
\end{tabular}

F-test showed that $\mathrm{F}$ is highly significant for all of Self-esteem and defeatist behavior and its domains, thus we can assume that there is a linear relationship between the variables in our model. Which indicates that the regression model predicts the dependent variable significantly well, where $\mathrm{p}<0.000$, which is less than 0.05 , and indicates that, overall, the regression model statistically significantly predicts the defeatist behavior.

To predict the defeatist behavior with its dimensions from self-esteem, the following table provides the necessary information. 
Table 6. Coefficient

\begin{tabular}{|c|c|c|c|c|c|c|}
\hline \multirow{2}{*}{\multicolumn{2}{|c|}{ Dependent Variables }} & \multicolumn{2}{|c|}{ Unstandardized Coefficients } & \multirow{2}{*}{$\begin{array}{c}\text { Standardized Coefficients } \\
\text { Beta } \\
\end{array}$} & \multirow{2}{*}{$\mathrm{T}$} & \multirow{2}{*}{ Sig. } \\
\hline & & $\mathrm{B}$ & Std. Error & & & \\
\hline \multirow{2}{*}{ Feeling of guilt } & Constant & 5.053 & 0.542 & & 9.328 & 0.000 (a) \\
\hline & Self-esteem & -0.095 & 0.034 & -0.405 & -2.769 & 0.009 \\
\hline \multirow{2}{*}{ Withdrawal } & Constant & 6.056 & 0.513 & & 11.815 & $0.000(a)$ \\
\hline & Self-esteem & -0.159 & 0.032 & -0.620 & -4.933 & 0.000 (a) \\
\hline \multirow{2}{*}{ Self-destruction } & Constant & 5.523 & 0.305 & & 18.091 & 0.000 (a) \\
\hline & Self-esteem & -0.122 & 0.019 & -0.711 & -6.321 & 0.000 (a) \\
\hline \multirow{2}{*}{ Fear from the failure } & Constant & 6.120 & 0.398 & & 15.387 & 0.000 (a) \\
\hline & Self-esteem & -0.160 & 0.025 & -0.714 & -6.375 & 0.000 (a) \\
\hline \multirow{2}{*}{ Low ego } & Constant & 6.007 & 0.377 & & 15.930 & 0.000 (a) \\
\hline & Self-esteem & -0.157 & 0.024 & -0.728 & -6.623 & 0.000 (a) \\
\hline \multirow{2}{*}{ Social exclusion } & Constant & 5.924 & 0.347 & & 17.061 & 0.000 (a) \\
\hline & Self-esteem & -0.151 & 0.022 & -0.741 & -6.886 & 0.000 (a) \\
\hline \multirow{2}{*}{ Total Defeatist Behavior } & Constant & 5.823 & 0.278 & & 20.328 & 0.000 (a) \\
\hline & Self-esteem & -0.143 & 0.018 & -0.794 & -8.169 & $0.000(a)$ \\
\hline
\end{tabular}

It can be concluded from Table 6 that self-esteem significance is statistically significant at level $(\propto \leq 0.05)$ on the defeatist behavior dimensions, so it is possible to predict the defeatist behavior and its types among the female undergraduate students according to the following equations, using the unstandardized coefficient value of (B).

The regression equation will be as follow:
a) (Feeling of guilt $)=5.053+(-0.095 *$ Self-esteem)
b) $($ Withdrawal $)=6.056+(-0.159 *$ Self-esteem $)$
c) $($ Self Destruction $)=5.523+(-0.122 *$ Self-esteem $)$
d) $($ Fear of Failure $)=6.120+(-0.160 *$ Self-esteem $)$
e) $($ Low Ego $)=6.007+(-0.157 *$ Self-esteem $)$
f) $($ Social Exclusion $)=5.924+(-0.151 *$ Self-esteem $)$
g) $($ Defeatist Behavior $)=5.823+(-0.143 *$ Self-esteem $)$

Based on the above results, it can be said that self-esteem, being one of the individual's strong personality pillars, is not easily influenced by different external threats especially that it represents in its essence the evaluation the individual sets for himself as a whole. In other words, it is formed as a result of several accumulated experiences making it difficult to totter and collapse. Also, this result agrees with Eric Erickson's theory about human development, since he sees that the individual's interest in preserving the Ego-Integrity is accompanied by the increased acceptance of the individual's role in his life which creates in him feeling of self-worth and self-effectiveness as a result of maturity (Erikson, 1982).

Based on that, we can conclude that female students with high levels of self-esteem were fewer defeatists, which means there is an inverse relationship between self-esteem and the defeatist behavior among undergraduate students. This finding can be attributed to the fact that the defeatist behavior is a materialized belief inside the person during his life years making him predict and adopt the defeatist view, as confirmed by Salama (2007), who indicated that there are a number of factors that help in the creation of the defeatist behavior within the individual. Some of these factors biological, others are social, such as the nature of the social upbringing that helps the individual acquire the prevailing values, traditions and attitude in his society, also social factors determine if the individual will be optimistic or pessimistic in handling the social situations he faces in his life.

The reason for the negative correlation between self-esteem and the defeatist behavior regarding the social factors is because of the influence of accumulated experiences of frustration and failure the individual acquires during his life imposing on him a general negative expectation about his surroundings and the future events, which weakens his self-trust, making him doubt his competence, ability and effectiveness in facing the different situations and achieving success, leading to low level of self-esteem.

Results of this research were supported by results of some studies about the relationship between self-esteem and the defeatist behavior including: (Al-Tameemi, 2013; Kareem \& Fadel, 2016; Arabeyat \& Al-Zghool, 2008). 
Results of these studies confirmed the presence of negative relationship between self-esteem, including its different dimensions, and defeatism, indicating that the higher the students' self-esteem is, the lower the level of their defeatist behavior becomes.

\section{Recommendations}

In the light of the results and the previous studies, it is recommended that educational centers like universities pay more attention to developing counseling programs for adults to know how to plan for the future and how to formulate their life objectives and work to raise their self-esteem.

\section{References}

Abdel-Khalek, A., Korayem, A., \& El-Nayal, M. (2012). Self-esteem among college students from four Arab Countries. Psychological Reports, 110, 297-303. https://doi.org/10.2466/07.09.17.PR0.110.1.297-303

Abu-Ghali, I. (2012). Self-Esteem and its Relationship with life pressures among the Married undergraduate female students at Al-Aqsa University. Journal of the Islamic University for the Educational and Psychological Studies, 2(1), 619-654.

Abu-Halawa, M. (2015). Psychological Defeat, its essence indicators, determinants, consequence and prevention from it. Issues of the Arab psychological Network, Series of the Electronic Book, Number 28.

Abu-Moghli, S. (2002). The Child's Social Upbringing. Dar Al-Yazoori for Publication, Amman, Jordan.

Al-Dojaili, S., \& Al-Ani, I. (2018). Self-Defeatist in light of some variables among the sixth Basic Grade students. Psychological Researches Center, 29, 407-464.

Al-Mtairi, M. (2010). Types of the Popular Behavior in our Society. Dar Al-Hamed For Publication, Amman, Jordan.

Al-Shafi, N. (2017). Psychological Defeat As a Predictor of the Attitude Sexual Harassment Among a Sample of Males University Students. Educational Journal/University of Kuwait, 32(125), 145-191.

Al-Tameemi, L. (2013). Self-defeated Personality and Its Relation with Psychological and social status of Al-Qadisiya University Students (Unpublished master thesis), Baghdad University.

Al-Zu'bi, A. (2005). The Relationship between Depression and Self-Esteem Among the secondary stage students from both Genders. Journal of Educational sciences, Qatar University, 8, 57-80.

Arabeyat, A., \& Al-Zghool, I. (2008). The Differences in Self-Esteem Level among Mu'ta University Students According to gender, major and Academic level variables. Journal of Educational and Social Sciences, Al-Bahrain University, 9(1), 37-53.

Atkinson, B. E. (2017). The Self-DISS: A Comprehensive MesSureof self-Defeating Interpersonal style. Electronic thesis and Dissertation Repository. https://doi.org/10.1037/t73385-000

Benyamini, Y., Leventhal, H., \& Leventhal, E. A. (2004). Self-rated oral health as an independent predictor of self-rated general health, self-esteem and life satisfaction. Social Science \& Medicine, 59(5), 1109-1116. https://doi.org/10.1016/j.socscimed.2003.12.021

Blascovich, J., \& Tomaka, J. (1991). Measures of self-esteem. Measures of personality and social psychological attitudes, 1, 115-160. https://doi.org/10.1016/B978-0-12-590241-0.50008-3

Brownson, C., \& Hartzler, B. (2000). Defeat your self-defeating behavior: Understanding and overcoming harmful patterns. Clearinghouse for Structured-Thematic Groups \& Innovative Programs. Austin: University of Texas at Austin.

Chang, S. (2006). Testing the self-Care self-efficacy enhancement Program aimed at improving BADL performance for Chinese nursing home Elders. Gerontology, 67, 805-817.

Coopersmith, S. (1981). The antecedents of self-esteem. California, Polo alto, counsel ting psychologists press.

Erikson, E. (1982). The life cycle completed. New York. Norton.

Fakhri, N. (2014). Rational and Irrational Thinking and its influence on the personality. Journal of the Army, 225 .

Hamid, M., Hussein, M., Abu-Taleb, F., \& Abu-Taleb, S. (2015). Psychology Principles. Publications of Open Jerusalem University, Amman, Jordan.

Hammood, M. (2000). Self-Esteem in The Studying Behavior of the Primacy State Students and Its Relationship with some of the variables. Arab Journal for Education, 2(20), 124-149. 
Hasan, O., \& Ali, D. (2014). Social Anxiety and Its Relation with Self-Esteem Among female students of Faculty of sport. Al-Qadisiya Journal for Sport Education Sciences, 14(2), 92-108.

Heritage, J. (2013). The Relationship of dominance, self-esteem, and life satisfaction to select variables. Paper Presented at the annual meeting of the Middle Tennessee psychologically Association (Nashville, April 26).

Kabatay, R. T. (1999). Self-Defeating Personality and Learned Helplessness.

Kareem, N., \& Fadel, T. (2016). Measuring the Defeatist Behavior Among the University Students. Journal of Faculty of Basic Education, 22, 669-704.

Lahey, B. B. (2000). Psychology (7th ed.). Chicago, USA.

Macfie, J., Cicchetti, D., \& Toth, S. L. (2001). The development of dissociation in maltreated preschool-aged children. Development and Psychopathology, 13(2), 233-254. https://doi.org/10.1017/S0954579401002036

Maslow, A. (1970). Motivation and Personality (2nd ed.). Princeton: N. J.: Von Nostrad.

Meifen, W., \& Tsun, Y. (2007). Testing a Conceptual Model of Working through Self-Defeating Patterns. Journal of Counseling Psychology, 45, 295-305. https://doi.org/10.1037/0022-0167.54.3.295

Mik, K. et al. (2010). Personal defeatism "Comparison Study between urban and villages" among Selangor University, Malaysia. Educational Journal, 23(3), 104-133.

Mohammad, H. (2016). Irrational Thoughts and the Relationship with the Defeatist Behavior Among the Undergraduate Students Major Kindergarten. Journal of Faculty of Education, Waset University, 24, 321-362.

Moray, E. (1988). Motivation and Emotion (Translated by S. A. Dar Al-Shorooq).

Okasha, A. (1998). Contemporary Psychological Medicine. The Anglo Library, Cairo, Egypt.

Rattan, N., Kang, S., Thakur, N., \& Parthi, K. (2006). State Self-Esteem in Relation to Weight Locus of Control amongst Adolescents. Journal of Indian Association for Child and Adolescent Mental Health, 2(1), 31-34.

Robinson, J. P., Shaver, P. R., \&. Wrightsman, L. S. (Eds.). Measures of personality and social psychological attitudes (pp. 115-160). San Diego: Academic Press.

Rosenberg, M. (1989). Society and the adolescent self-image. Middletown CT: Wesleyan University Press.

Sa'aydeh, N. (2007). Self-concept and its Relationship with some of the Demographic Variables. Journal of Educational and Social Sciences, Al-Bahrain University, 8(3), 85-106.

Salama, A. (2007). Social Psychology. Dar Al-Yazoori for Publication, Amman, Jordan.

Williams, B. (1980). Attention in handbook of general psychology. New York, Benjamin Rwolman, Prentice-Hall.

\section{Copyrights}

Copyright for this article is retained by the author(s), with first publication rights granted to the journal.

This is an open-access article distributed under the terms and conditions of the Creative Commons Attribution license (http://creativecommons.org/licenses/by/4.0/). 